UDC 667.6; 614.84

DOI: $10.15587 / 2706-5448.2021 .237982$

Article type «Reports on Research Projects»

\section{Oleksandr Hryhorenko, Yevheniia Zolkina}

\title{
DEVELOPMENT AND OPTIMIZATION OF FIRE-PROTECTIVE COATING COMPOSITION BASED ON EPOXYPOLYMERS
}

The object of research is intumescent fire retardant coatings based on epoxy resins. The research is aimed at the development of mathematical models of the dependence of the swelling rate of intumescent fire retardant coatings on their composition. Considering the complexity of the processes during the formation of a protective carbon layer, it is advisable to select the optimal ratio of the components of an intumescent fire retardant coating experimentally, followed by the construction of mathematical dependences of the swelling ratio on the coating composition. Therefore, experimental studies aimed at developing and optimizing the composition of an intumescent fire retardant coating based on epoxy polymers are an important task. The studies were carried out in accordance with the theory of planning experiments with the construction of an orthogonal compositional plan of the second order. A linear swelling factor was chosen as the response function. Compositions based on the ED-20 epoxy oligomer, cured with polyethylene polyamine and filled with ammonium polyphosphate, aluminum hydroxide, and graphite additive were used for the study. Based on the results of processing the experimental results, a regression equation was obtained and response surfaces were constructed that describe the dependence of the linear swelling coefficient Cs of an intumescent composition based on an epoxy oligomer on the content of ammonium polyphosphate, aluminum hydroxide and graphite additive. A complex relationship is shown between the content of components and the linear swelling coefficient Cs with different ratios of the components. The optimum by the linear swelling coefficient (Cs=68.1) content of the components in the epoxy polymer was determined, amounting to 20 wt. including for ammonium polyphosphate, 15 mass parts including for aluminum hydroxide and 3 mass parts for the graphite additive. However, with such a ratio, the «self-extinguishing» condition is not met (Cs=27\%). Filling the composition with ammonium polyphosphate in an amount of 26.3 mass parts including, aluminum hydroxide 25 mass parts and 3.5 mass parts including graphite additives allows to get an intumescent fire retardant coating with a swelling ratio Cs over 63 and a reduced level of flammability (Ci=31\%).

Keywords: intumescent fire retardant coatings, swelling ratio, epoxy polymer, ammonium polyphosphate, aluminum hydroxide, graphite additive.

\section{Hoze to cite}

Hryhorenko, O., Zolkina, Y. (2021). Development and optimization of fire-protective coating composition based on epoxypolymers. Technology Audit and Production Reserves, 4 (3 (60)), 18-20. doi: http://doi.org/10.15587/2706-5448.2021.237982

\section{Introduction}

The development of fire retardant coatings that swell under the influence of high temperatures is a complex scientific and practical task that requires a clear understanding of the role of each of the components in the intumescent system [1,2]. Typically, typical intumescent fire protection coatings (IPC) used for fire protection are multicomponent systems, which generally consist of:

- film former (binder);

- an inorganic acid or substance, it is released at a temperature of $100-250{ }^{\circ} \mathrm{C}$;

- compounds with a high carbon content - coke-flawless; - gas generators (substances that are capable of releasing a significant amount of non-combustible gases during thermal destruction) [3, 4].
Proceeding from the set of operational characteristics high strength indicators, chemical and atmospheric resistance, adhesion to many materials - the development of IPP based on epoxy resins is promising [5, 6]. Taking into account the complexity of the processes during the formation of a protective carbon layer, the selection of the optimal ratio of the components of an intumescent fire retardant coating is advisable to carry out experimentally, followed by the construction of mathematical dependences of the swelling ratio on the composition of the coating [7]. Therefore, experimental studies are aimed at developing and optimizing the composition of an intumescent fire retardant coating based on epoxy polymers is an urgent task. The object of the research is intumescent fire retardant coatings based on epoxy resins. The aim of research is to develop mathematical models of the dependence of the swell- 
ing rate of intumescent fire retardant coatings on their composition.

\section{Methods of research}

Let's use compositions based on the ED-20 epoxy oligomer, hardened with polyethylene polyamine (PEPA) hardener and filled with the PFA:Al(OH) $)_{3}: T G$ system. Ammonium polyphosphate (PFA) was used as a source of inorganic acid, the film former was used as a carbon source, and a graphite additive (TG) was additionally introduced, and aluminum hydroxide $\left(\mathrm{Al}(\mathrm{OH})_{3}\right)$ was used as a gas generator.

The studies were carried out according to the theory of planning experiments with the construction of an orthogonal compositional plan of the second order [8]. The linear swelling coefficient $C_{s}$ was chosen as the response function; it was determined according to the method described in [9]. The intervals of variation and the nominal values of the factors of the variables are presented in Table 1.

Table 1

The significance of the factors and their intervals of variation

\begin{tabular}{|l|c|c|c|}
\hline \multicolumn{1}{|c|}{ Factors } & \multicolumn{3}{c|}{ Levels of variation } \\
\hline Encoded values & -1 & 0 & +1 \\
\hline Ammonium polyphosphate content, m. p. $(x 1)$ & 20 & 25 & 30 \\
\hline Aluminum hydroxide content, m. p. $(x 2)$ & 15 & 20 & 25 \\
\hline Content of graphite additive, m. p. $(x 3)$ & 2 & 4 & 6 \\
\hline
\end{tabular}

The construction of response surfaces and optimization were carried out using the Maple software package.

\section{Research results and discussion}

The expanded planning matrix and the results of the experiment in the implementation of the orthogonal central compositional plan of the second order are shown in Table 2.

Table 2

Extended planning matrix and experimental results for the implementation of a second-order orthogonal central compositional plan

\begin{tabular}{|c|c|c|c|c|c|c|c|c|c|}
\hline \multirow{2}{*}{$\begin{array}{c}\text { Experi- } \\
\text { ment }\end{array}$} & $x_{0}$ & $x_{1}$ & $x_{2}$ & $x_{3}$ & $x_{1} x_{2}$ & $x_{1} x_{3}$ & $x_{2} x_{3}$ & \multicolumn{2}{|c|}{$\Gamma_{s}$} \\
\hline 1 & 1 & 1 & 1 & 1 & 1 & 1 & 1 & 49.5 & 47 \\
\hline 2 & 1 & 1 & 1 & -1 & 1 & -1 & -1 & 57 & 54.5 \\
\hline 3 & 1 & 1 & -1 & 1 & -1 & 1 & -1 & 21 & 19 \\
\hline 4 & 1 & 1 & -1 & -1 & -1 & -1 & 1 & 19.5 & 17.5 \\
\hline 5 & 1 & -1 & 1 & 1 & -1 & -1 & 1 & 30 & 31 \\
\hline 6 & 1 & -1 & 1 & -1 & -1 & 1 & -1 & 52.5 & 51.5 \\
\hline 7 & 1 & -1 & -1 & 1 & 1 & -1 & -1 & 57.5 & 55.5 \\
\hline 8 & 1 & -1 & -1 & -1 & 1 & 1 & 1 & 62 & 63 \\
\hline 9 & 1 & 0 & 0 & 0 & 0 & 0 & 0 & 57 & 55.5 \\
\hline 10 & 1 & 1.215 & 0 & 0 & 0 & 0 & 0 & 34.5 & 36 \\
\hline 11 & 1 & -1.215 & 0 & 0 & 0 & 0 & 0 & 56 & 56.5 \\
\hline 12 & 1 & 0 & 1.215 & 0 & 0 & 0 & 0 & 65 & 62.5 \\
\hline 13 & 1 & 0 & -1.215 & 0 & 0 & 0 & 0 & 52 & 51.5 \\
\hline 14 & 1 & 0 & 0 & 1.215 & 0 & 0 & 0 & 42 & 40.5 \\
\hline 15 & 1 & 0 & 0 & -1.215 & 0 & 0 & 0 & 53 & 55 \\
\hline
\end{tabular}

Note: $y_{u 1}, y_{u 2}$ - linear swelling coefficient (dimensionless quantity)
According to the results of processing the experimental results, the regression coefficients were obtained and their significance was determined according to the Student's criterion. The reproducibility of the experiments was checked by the Cochran test. Checking the adequacy of the model - by Fisher's criterion. After eliminating insignificant coefficients and switching to the usual form of writing, the regression equation looks like:

$$
\begin{aligned}
& C_{s}=58.09-7.72 x_{1}+3.98 x_{4}-4.47 x_{3}+12.75 x_{1} x_{4}+ \\
& +2.69 x_{1} x_{3}-3.06 x_{4} x_{3}-8.25 x_{1}^{2}-6.98 x_{3}^{2} .
\end{aligned}
$$

The analysis of the regression equation showed that the model is adequate at a significance level of 0.05 . The obtained mathematical model adequately describes the dependence of the linear swelling coefficient of $C_{s}$ to the epoxy polymer within the range of varying factors: the content of ammonium polyphosphate is $20-30$ mass parts by weight, aluminum hydroxide is $15-25$ mass parts by weight, and the graphite additive is $2-6$ mass parts by weight and under test conditions are determined by the method described in [9] (test temperature in a muffle furnace $340 \pm 5{ }^{\circ} \mathrm{C}$, temperature exposure time $-20 \mathrm{~min}$.).

The response surfaces (Fig. 1) were constructed using the regression equation (1), which describe the dependence of the linear swelling coefficient $C_{s}$ of an intumescent composition based on an epoxy oligomer on the content of ammonium polyphosphate, aluminum hydroxide, and graphite additive.

The response surfaces are shown in Fig. 1 show a complex relationship between the content of components in the epoxy polymer filled with the PFA: $\mathrm{Al}(\mathrm{OH})_{3}: \mathrm{TG}$ system and the linear swelling coefficient $C_{s}$ at different ratios of the components.

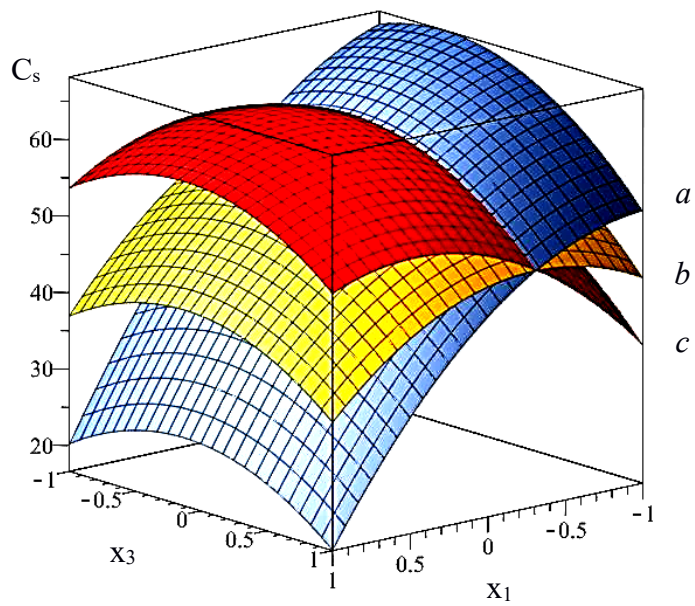

Fig. 1. Dependence of the expansion rate $C_{s}$ of the intumescent composition of the PFA: $\mathrm{Al}(\mathrm{OH})_{3}$ : TG system based on the epoxy oligomer on the content of ammonium polyphosphate $x_{1}$ and graphite additive $x_{3}$ with the amount of aluminum hydroxide $x_{2}: a-x_{2}=-1 ; b-x_{2}=0 ; c-x_{2}=1$

The study of the regression equation (1) and the determination of the optimal content of the components was carried out using the Maple software package. It was found that the extremum of the function is on the verge of varying $x_{1}$ and $x_{2}$ with a minimum content of these components. And also for $x_{3}$ equal to -0.51 , or when recalculating from the coded values of the variables to normal values: ammonium polyphosphate $\left(x_{1}\right)-20$ mass parts, aluminum hydroxide $\left(x_{2}\right)-15$ mass parts, graphite 
additive $\left(x_{3}\right)-3$ mass parts. With such a ratio of the components, the $C_{s}$ function reaches a value of 68.1 .

Studies [10] have shown that the low content of ammonium polyphosphate and aluminum hydroxide in epoxy polymers (20 and 15 mass parts, respectively) does not provide the requirements for the incombustibility of the coating. The limiting oxygen index with such a ratio of components is only $27 \%$, whereas in order for the condition of «self-extinguishing» to be fulfilled - that is, the coating does not support combustion - The limiting oxygen index must have a value of at least $29 \%$.

As can be seen from Fig. 1, when filling the composition of the PFA: $\operatorname{Al}(\mathrm{OH})_{3}: \mathrm{TG}$ system within the PFA 25-29 mass parts including, $\mathrm{Al}(\mathrm{OH})_{3}-25$ mass parts, TG 3.2-4.2 mass parts there is an extremum with a slightly lower value of the $C_{s}$ function, reaches 63 . Therefore, a study was carried out of the function to determine the local extremum for values of the content of ammonium polyphosphate more than 25 mass parts (the range of variation $x_{1}$ from 0 to 1 ) at values of the graphite additive $x_{3}$ and aluminum hydroxide $x_{2}$ within the range of variation from -1 to 1 . The local extremum of function (1) for the given limits of variation is at the values of the factors of the variables $x_{1}=0.26$, $x_{3}=-0.27$ and $x_{2}=1$. This in terms of the coded values of the variables in the normal is 26.3 mass parts including ammonium polyphosphate, 25 mass parts including aluminum hydroxide and 3.5 mass parts including graphite additives. In this case, the value of the $C_{s}$ function reaches 63.3, which is quite enough for the formation of a reliable heat-insulating barrier. The limiting oxygen index at this ratio of ammonium polyphosphate and aluminum hydroxide, according to studies [10], is $31 \%$.

Further studies will be aimed at determining the dependence of the performance characteristics of IPPs based on epoxy polymers filled with the PFA:Al( $\mathrm{OH})_{3}$ :TG system.

\section{Conclusions}

Thus, on the basis of the experiment carried out, the effect of ammonium polyphosphate, aluminum hydroxide and graphite additive on the swelling rate of an intumescent fire retardant coating based on an epoxy oligomer was investigated. A mathematical model has been obtained that adequately describes the dependence of the linear swelling coefficient of an epoxy polymer filled with ammonium polyphosphate (within 20-30 mass parts by weight), aluminum hydroxide (15-25 mass parts by weight) and a graphite additive (2-6 mass parts by weight) at test temperature $340{ }^{\circ} \mathrm{C}$ and allows to purposefully regulate the expansion rate of the PPI filled with the system under study. The content of PFA, $\mathrm{Al}(\mathrm{OH})_{3}$ and TG components in the epoxy polymer, which is optimal in terms of the linear swelling coefficient, has been determined, which makes it possible to obtain an intumescent fire retardant coating with a high swelling factor ( $C_{s}$ more than 63) and a reduced flammability level $\left(C_{i}=31 \%\right)$.

The research results can be used in the future to develop new and improve existing fire retardant coatings and materials based on epoxy resins.

\section{References}

1. Andryushchenko, L., Borysenko, V., Kudin, O., Goroneskul, M. (2019). Intumescent fire protective coatings in modern building (review). Problems of Emergency Situations, 1 (29), 121-138.

2. Alongi, J., Han, Z., Bourbigot, S. (2015). Intumescence: Tradition versus novelty. A comprehensive review. Progress in Polymer Science, 51, 28-73. doi: https://doi.org/10.1016/ j.progpolymsci.2015.04.010

3. Vakhitova, L. N., Taran, N. A., Drizhd, V. L., Prydatko, S. P. (2015). Fire-retardant efficiency of intumescentcoating in the presenceof nanosized compounds under hydrothermal ageing. Odesa National University Herald. Chemistry, 20 (2 (54)), 83-92. doi: https://doi.org/10.18524/2304-0947.2015.2(54).50634

4. Zybina, O. A. (2015). Teoreticheskie printsipy $i$ tekhnologiya ognezaschitnyh vspuchivayuschihsya materialov. SanktPeterburg, 260.

5. Stoye, D., Freitag, W. (Eds.) (1998). Paints, coatings and solvents. John Wiley \& Sons. doi: https://doi.org/10.1002/9783527611867

6. Silveira, M. R. da, Peres, R. S., Moritz, V. F., Ferreira, C. A. (2019). Intumescent Coatings Based on Tannins for Fire Protection. Materials Research, 22 (2). doi: https://doi.org/10.1590/19805373-mr-2018-0433

7. Trifonova, O. N. (2013). Optimization of fire retardance for metal structures. Pozharovzryvobezopasnost', 22 (1), 58-62. doi: https://doi.org/10.18322/pvb.2018.22.01.58-62

8. Vinarskiy, M. S., Lur'e, M. V. (1975). Planirovanie eksperimenta v tekhnologicheskih issledovaniyah. Kyiv: Tekhnika, 168.

9. Hryhorenko, O., Zolkina, Y. (2020). Study of the dependence of the expansion rate of epoxy polymer on the content of ammonium polyphosphate, pentaerythritol and intercalated graphite. Problemy pozharnoy bezopasnosti, 48, 30-36.

10. Hryhorenko, O. M., Lypovyi, V. O., Pyshniak, A. M. (2016) Studies of influence of flammability and multiplicity swelling epoxy-polymer of contents MAP and alumina trihydrate. Problemy pozharnoy bezopasnosti, 39, 73-77.

Oleksandr Hryhorenko, PhD, Associate Professor, Department of Fire and Technological Safety of Facilities and Technologies, National University of Civil Defence of Ukraine, Kharkiv, Ukraine, ORCID: https://orcid.org/0000-0003-4629-1010

$\triangle$ Yevheniia Zolkina, Adjunct, National University of Civil Defence of Ukraine, Kharkiv, Ukraine, e-mail: evheniiazolkina@gmail.com, ORCID: https://orcid.org/0000-0003-2562-2546

$\triangle$ Corresponding author 